\title{
Austerity threatens pharma beyond borders of cost cutters
}

With austerity measures tightening across Europe, and governments looking for quick cost-saving wins, drug prices have found themselves on the chopping board across the continent. But while politicians rejoice at having figured out how to stretch shrinking healthcare budgets, the pharmaceutical sector wonders where it will end."

If you cut revenue streams, then clearly that's something the manufacturers need to absorb elsewhere," says Colin Mackay, a spokesman for the European Federation of Pharmaceutical Industries and Associations, a Belgium-based pharmaceutical lobby group. $\mathrm{He}$ points to employment and drug research and development programs as probable victims.

In Greece, where financial instability has been particularly severe, the government implemented sweeping average drug price cuts of $21.5 \%$ in May. These emergency reductions are due to expire in August. Nevertheless, Danish diabetes giant Novo Nordisk, along with some smaller companies, subsequently withdrew products over fears of operating at a loss. Novo Nordisk eventually struck a deal with the government in mid-June to start resupplying its insulins, but not before incurring the opprobium of patient groups.

Yet although the Greek drama has captured the headlines, other governments have been leading the charge for cheaper drugs.

Spain slashed 25\% off generics in March and

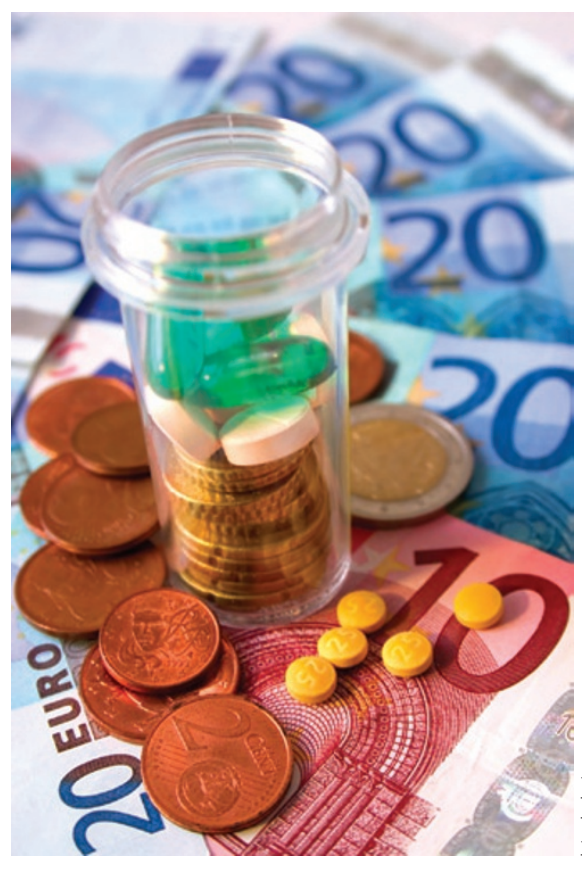

Paying the price: Drugmakers hit by lower prices.

simultaneously revised its pricing scheme to drive down the price of branded drugs. In May, the country forced firms to sacrifice a further $7.5 \%$ of their revenue for patent-protected meds. All told, these cuts will cost the pharma sector, or save Spain, $€ 1.3$ billion ( $\$ 1.6$ billion).

\section{Pharma fesses up to freebies}

Pharmaceutical companies have long handed out free drug samples as a way to promote their products directly to physicians. Although watchdogs have estimated that the total retail price of freebies exceeds $\$ 18$ billion per year ( $N$. Engl. J. Med. 357, 673-681, 2007), the industry has traditionally kept such information a closely guarded secret. Thanks to the new US healthcare bill, however, starting in 2012 pharma firms will be compelled to disclose their giveaways.

"Samples are a very important marketing tool," says Allan Coukell, director of the Pew Prescription Project. "This [disclosure] will allow policymakers to get a better picture of what's clearly one driver of prescribing practices and of costs."

Ahead of the law change, several US-based companies voluntarily reported their donations from 2007 to Congress. Some companies counted samples by dose, whereas others counted by unit; prices are based on either market price or wholesale cost.

\begin{tabular}{lll} 
& Samples & Value (\$ million) \\
\hline Pfizer & 101 million & 2,700 \\
Merck & 39 million & 356 \\
Eli Lilly & 33 million & 67 \\
Wyeth (now part of Pfizer) & 52 million & 64 \\
Abbott & 16 million & 32 \\
Baxter & 33,000 & 7 \\
\hline
\end{tabular}

Source: Dow Jones

Germany also started making moves in March to chop up to $16 \%$ off what it pays for drugs and to overhaul its pricing system.

Other countries, including Italy, France and Ireland, are also considering, or have already introduced, cuts of one form or another. Because many European countries set prices for their drugs by taking into account the average costs in several other countries, returns might fall even in markets that don't take cost-saving measures.

"It's unsustainable for the pharmaceutical industry to take any more hits," cautions Julián Zabala, a spokesman for the industry association Farmaindustria in Madrid.

\section{Another hurdle}

For Christopher McCabe, a health economist at the University of Leeds, UK, prices may have a chance to rebound once budgets start to rise again. That is, he says, if companies can overcome the emerging hurdle of value-based pricing (VBP), in which drug prices directly reflect health benefits.

The UK's new coalition government wants to introduce VBP by 2014 . And the National Institute for Health and Clinical Excellence (NICE) - which decides which drugs are affordable for the UK's National Health Service-is already experimenting with the paradigm. Comparative effectiveness studies are being used to assess whether multiple sclerosis drugs are priced appropriately, for instance, and reimbursements for nonresponders are being used to improve the cost effectiveness of cancer therapies.

"Some versions of these are undoubtedly price discounts in disguise," says McCabe. As such schemes evolve and continue to catch on across Europe, he says, companies will have to avoid the riskier clinical trials, as their high costs inflate the prices of drugs that do make it to market.

The sooner pharma factors VBP into research and development decisions, adds McCabe, "the quicker it will find it can continue to make very healthy profits."

Asher Mullard, London 